\title{
SUBLUXATION OF THE KNEE AS A COMPLICATION OF FEMORAL LENGTHENING BY THE WAGNER TECHNIQUE
}

\author{
DONALD C. JONES, COLIN F. MOSELEY
}

\author{
From the Hospital for Sick Children, Toronto
}

\begin{abstract}
Twenty-one patients with leg-length inequality underwent femoral lengthening using the Wagner technique. When reviewed, seven were found to have varying degrees of posterior subluxation of the knee. Critical assessment demonstrated that each of these was associated with a hypoplastic femur. It is postulated that posterior displacement of the tibia on the femur occurred as a result of the distal femoral and intraarticular bony deficiencies.
\end{abstract}

The first femoral lengthening was accomplished by Codivilla in 1905. Since that time, numerous surgeons have tried to perfect this procedure. Magnuson reported on a series of 14 femoral lengthenings in 1913, but it was not until 1921 that a distraction device was used (Putti 1921). Abbott (1927), Compere (1936), McCarroll (1950), and Bost and Larsen (1956) continued the process of improving upon the technique. Despite these efforts, interest in femoral lengthening waned as many surgeons became sensitised to the numerous serious complications which can occur (McCarroll 1950; Bost and Larsen 1956; Sofield, Blair and Millar 1958; d'Aubigné and Dubousset 1971).

In the last decade the introduction of the Wagner lengthening device and his surgical technique have renewed interest in the procedure (Wagner 1978). Wagner's apparatus offers a lightweight yet rigid and durable piece of equipment with which the patient can be mobile; his technique utilises sound surgical principles which help to circumvent the complications experienced by earlier pioneers in this field. However, complications still exist.

During a four-year period at the Hospital for Sick Children, Toronto, 21 femoral lengthenings were performed by the Wagner technique. A retrospective study of these patients has revealed seven instances of posterior subluxation of the tibia on the femur. In the Englishspeaking literature, this problem is seldom mentioned; of 329 published cases of femoral lengthening since 1905 , only eight examples of posterior subluxation of the knee are reported (Bost and Larsen 1956; Westin 1967; Stephens 1983).

D. C. Jones, MD, Orthopedic Surgeon

Orthopedic and Fracture Clinic, 677 East 12th Avenue, Suite 210, Eugene, Oregon 97401, USA.

C. F. Moseley, MD, CM, FRCS(C), Orthopaedic Surgeon

Division of Orthopaedic Surgery, The Hospital for Sick Children, 555

University Avenue, Toronto, Ontario, Canada M5G IX8.

Requests for reprints should be sent to $\mathrm{Dr}$ C. F. Moseley.

(c) 1985 British Editorial Society of Bone and Joint Surgery

$0301-620 \times / 85 / 1001 \$ 2.00$

\section{MATERIAL AND METHODS}

Between the years 1974 and 1978, 21 Wagner femoral lengthenings were performed on 20 patients. There were 13 girls and 7 boys aged 2 to 14 years. The cause of the short femur was hypoplasia of the femur (14 cases), avascular necrosis of the proximal femoral epiphysis with subsequent shortening (2), neuromuscular growth disturbance (1), congenital dislocation of the hip with a false acetabulum (1), poliomyelitis or a similar disorder (2) and one growth disturbance secondary to a traumatised femoral epiphysis. Lengthenings of 3.0 to $10.0 \mathrm{~cm}$ were achieved. Because the procedures were performed at different ages and therefore on femora of different lengths, the actual lengthenings obtained will be referred to as a percentage of the initial length of the femur. In all the cases reviewed the Wagner surgical technique was used; this has been well outlined in previous articles (Hood and Riseborough 1981; Torode and Gillespie 1983).

\section{ILLUSTRATIVE CASE REPORTS}

Case 1. A three-year-old girl with a hypoplastic femur had a $10 \mathrm{~cm}$ leglength discrepancy. After two weeks of distraction marked loss of extension of the knee was noted; this led to the suspicion of subluxation, which was confirmed by radiography. The limb was placed in skeletal traction using a tibial pin and this was followed by serial extension plasters. Reduction was successful.

At follow-up there were few symptoms secondary to the knee instability. Examination revealed normal stability in the varus-valgus plane: however, a strongly positive anterior drawer sign with lateral translocation of the tibia on the femur was present when the knee was moved from 90 of flexion to full extension. There was also wellmarked anteromedial and some anterolateral rotatory instability.

Case 2. A three-year-old girl with a congenital hypoplastic femur had a leg-length discrepancy of $7 \mathrm{~cm}$. After the femoral osteotomy and application of the distraction device, the patient did extremely well for seven weeks. She obtained full knee extension and 90 of flexion During the eighth week she began to complain of hip pain and refused to carry out her exercises. A radiograph of her hip was normal. Her femoral measurement revealed $5.5 \mathrm{~cm}$ of lengthening and her range of knee movement was from 10 to 100 . She continued to show definite signs of discontent on exercising and her knee extension began to decrease. Four weeks later, radiographs showed posterior subluxation 
of the knee. Lengthening of the medial and lateral hamstrings permitted effortless reduction. After a short period of plaster immobilisation the knee remained reduced.

Case 3. A seven-year-old boy with a hypoplastic femur and congenital absence of the fibula had an $11 \mathrm{~cm}$ leg-length discrepancy. A lengthening of $6.5 \mathrm{~cm}$ had been achieved when radiographs showed posterior subluxation of the knee. His hamstring muscles were lengthened, the posterior half of the medial collateral ligament divided and a posterior capsulotomy performed; however, it was not until the anterior cruciate ligament also had been totally divided that the knee could be reduced. A flexion contracture remained, necessitating tibial pin traction followed by plaster immobilisation. Exercises were started shortly thereafter.

Case 4. A nine-year-old boy had an $11 \mathrm{~cm}$ leg-length inequality secondary to femoral hypoplasia. After only $1 \mathrm{~cm}$ of lengthening, posterior subluxation of the knee was noted. The femur was plated and bone grafted after $3.5 \mathrm{~cm}$ of length had been gained. After internal fixation of the femur, the knee was reduced and plaster applied. At the age of 13 years he had a second leg-lengthening; no evidence of subluxation of the knee developed during this second procedure.

Case 5. An 11-year-old girl with a hypoplastic femur had an $11 \mathrm{~cm}$ leglength discrepancy. Seven weeks and $7.5 \mathrm{~cm}$ of lengthening later. radiographs showed posterior subluxation of the knee and an associated depression fracture of the lateral tibial plateau (Figs 1 and 2). Lengthening of the hamstrings permitted complete reduction of the knee. She was held in an extension cast for six weeks. Once out of the cast, she was started on a vigorous physiotherapy programme; however, she once again subluxated posteriorly.

Case 6. An 11-year-old boy had a hypoplastic femur and fibular hemimelia. A Wagner lengthening of his femur, with simultaneous lengthening of his ipsilateral tibia, was undertaken in order to correct a $7 \mathrm{~cm}$ leg-length discrepancy. Pre-operatively his knee was unstable in the anteroposterior plane. After four weeks of distraction posterior subluxation of the knee was noted; this was easily reduced after hamstring lengthening and release of the posterior fascia.
Three years after these operations knee symptoms were minimal. He could skate and run without the knee giving way. There was minimal varus-valgus instability; however, he had a grossly positive anterior drawer sign with marked anteromedial and some anterolateral rotatory instability. There was a pivot slide but no overt pivot shift.

Case 7. A 14-year-old boy with a hypoplastic femur had had a femoral lengthening for an $8.5 \mathrm{~cm}$ discrepancy at the age of 11 . Unfortunately, he developed a severe pin track infection preventing plating and bone grafting of the distracted femur. When the distraction device was removed, his femur collapsed at the osteotomy site. losing $4.5 \mathrm{~cm}$ of length. Once the femur healed he opted for another leg-lengthening procedure. During distraction posterior subluxation of the knee occurred after only $2.5 \mathrm{~cm}$ of lengthening. The knee reduced after release of the iliotibial band and lengthening of the hamstring tendons. He subsequently developed a full range of movement in his knee except for a 5 flexion contracture.

\section{DISCUSSION}

Three factors were explored in an attempt to find a common denominator among the patients whose knees subluxated while undergoing femoral lengthening: age, percentage of the femur lengthened, and the aetiology of the leg-length discrepancy.

Age appeared to have no direct relationship to this complication. The patients ranged from 3 to 14 years of age without any specific age-related peak.

Four patients had undergone lengthening of more than $20 \%$ before subluxation occurred; however, the significance of this finding is not clear, since six of the uncomplicated lengthenings also had been lengthened by more than $20 \%$ and the three remaining cases

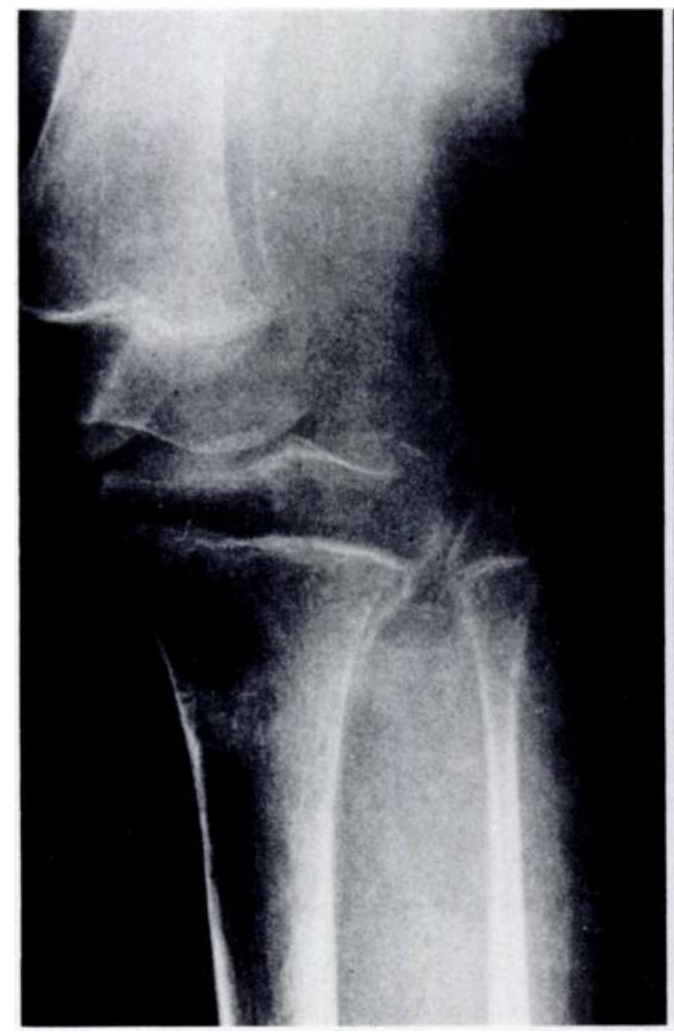

Fig. 1

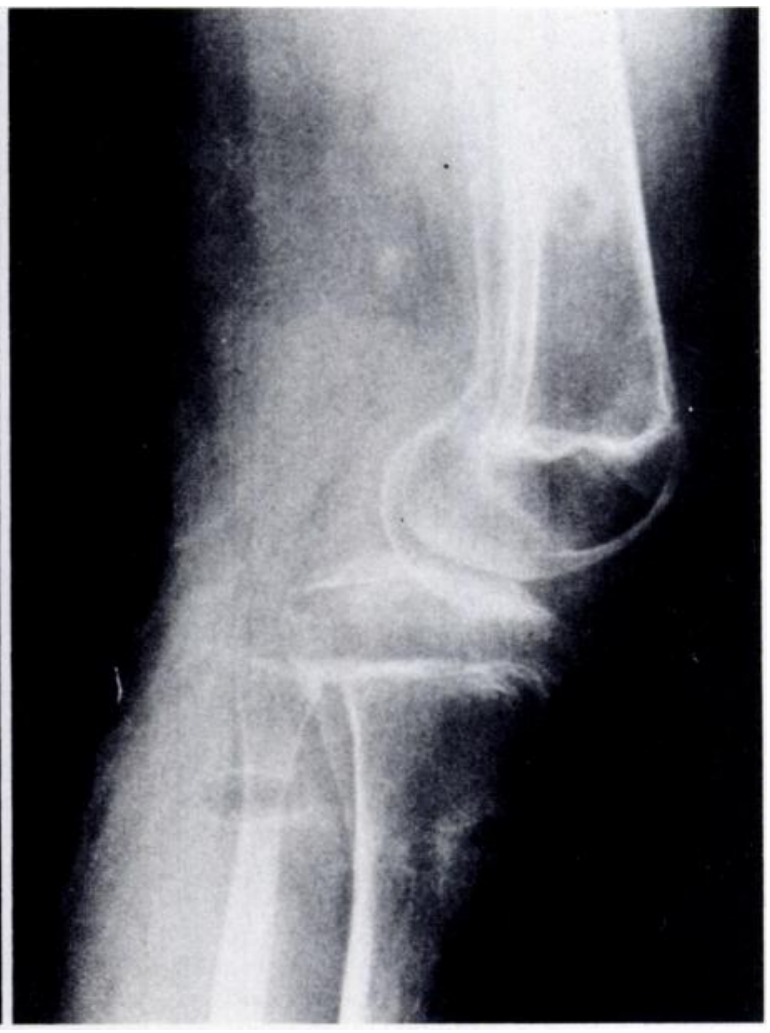

Fig. 2

Case 5. Posterolateral displacement of the tibia on the femur during lengthening procedure. Note the depression fracture of the lateral tibial plateau. 
of subluxation occurred with lengthenings of $7 \%$ or less, one having been distracted only $2.5 \%$ at the time of subluxation.

The only common denominator is that all seven cases involved patients with hypoplastic femora. It is worth noting that Westin's two cases of this complication also occurred in patients with hypoplastic femora as did Stephen's single case.

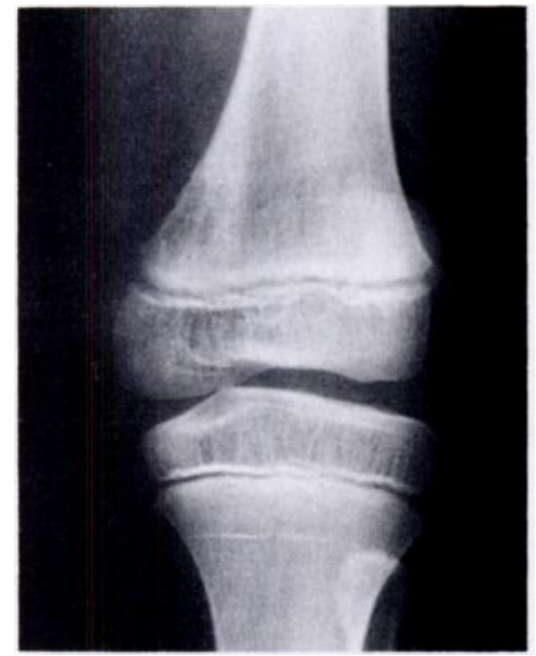

Fig. 3

Note the lateral femoral dysplasia, flattening of the lateral tibial plateau and tibial eminence hypoplasia.

Our patients with hypoplastic femora consisted of children with and children without proximal femoral changes, as classified by Amstutz (1975). The literature contains numerous descriptions of the morphological changes in the proximal end of hypoplastic femora; however, description of the distal end has been limited to Amstutz's mention of its small size. Torode and Gillespie (1983) have now demonstrated that patients with hypoplasia of the femur have dysplasia of the lateral femoral condyle of the femur (with varying degrees of instability of the knee), hypoplastic changes of the tibial eminence, and flattening of the lateral tibial plateau (Fig. 3). These findings are substantiated by the radiographs of the patients in this series. All seven patients whose knees subluxated had lateral femoral condylar dysplasia as well as flattening of the lateral tibial plateau. Because of this lateral compartmental dysplasia, we feel that the knees are predisposed to posterolateral subluxation. This type of subluxation has been mentioned by Manning (1978) although he could not formulate a reason for its occurrence.

From our study, several points emerge. First, the patient whose leg-length discrepancy is due to femoral hypoplasia, and who is a candidate for a femoral lengthening procedure, is also a candidate for posterior subluxation of the knee; the surgeon then has to consider whether a preliminary operation (lengthening of the hamstrings or supracondylar varus osteotomy of the femur) is indicated. Secondly, once the distraction process has begun great care should be given to the maintenance of knee extension. Thirdly, the surgeon should maintain a high index of suspicion and be alert to recognise the symptoms and signs which indicate subluxation; these may occur insidiously (almost overnight) and include pain in the knee or hip, rapid decrease in the ability to extend the knee, and sudden discomfort with physiotherapy. Finally, should full knee extension be lost, then careful clinical and radiological examination should be performed to exclude knee subluxation. Radiographs should not be limited to anteroposterior and lateral views of the elongated portion of the femur but should include a true lateral view of the knee.

Conclusion. During a four-year period, 21 patients underwent femoral lengthening using the Wagner technique. Seven cases of posterior knee subluxation developed. The complication occurred in those patients in whom femoral hypoplasia was the cause of the leg-length inequality. It is postulated that the hypoplastic changes about the knee predispose these individuals to this complication.

\section{REFERENCES}

Abbott LC. The operative lengthening of the tibia and fibula. J Bone Joint Surg $[\mathrm{Am}]$ 1927:9:128-52.

Amstutz HC. One-stage femoral lengthening. J Hosp Spec Surg 1975:1:57.

Bost FC, Larsen LJ. Experiences with lengthening of the femur over an intramedullary rod. J Bone Joint Surg $[\mathrm{Am}]$ 1956;38-A:567-84.

Codivilla A. On the means of lengthening, in the lower limbs, the muscles and tissues which are shortened through deformity. Am J Orthop Surg 1905:2:353-69.

Compere EL. Indications for and against the leg-lengthening operation: use of the tibial bone graft as a factor in presenting delayed union. non-union or late fractures. J Bone Joint Surg 1936;18:692-705.

d'Aubigné RM, Dubousset J. Surgical correction of large length discrepancies in the lower extremities of children and adults: an analysis of twenty consecutive cases. J Bone Joint Surg [Am] 1971:53-A:411-30.

Herron LD, Amstutz HC, Pakai DN. One stage femoral lengthening in the adult. Clin Orthop 1978:136:74-82.

Hood RW, Riseborough EJ. Lengthening of the lower extremity by the Wagner method: a review of the Boston Children's Hospital experience. J Bone Joint Surg $[\mathrm{Am}] 1981 ; 63-\mathrm{A}: 1122-31$.
McCarroll HR. Trials and tribulations in attempted femoral lengthening. J Bone Joint Surg [Am] 1950;32-A:132-42.

Magnuson PB. Lengthening shortened bones of the leg by operation: ivory screws with removable heads as a means of holding the two bone fragments. Surg Gynecol Obstet 1913:17:63-71.

Manning C. Leg lengthening. Clin Orthop 1978;136:105-10.

Putti V. The operative lengthening of the femur. JAMA 1921;77:934.

Sofield HA, Blair SJ, Millar EA. Leg lengthening: a personal follow-up of forty patients some twenty years after the operation. $J$ Bone Joint Surg $[\mathrm{Am}]$ 1958;40-A:311-22.

Stephens DC. Femoral and tibial lengthening. $J$ Pediatr Orthop $1983 ; 3(4): 424-30$.

Torode IP, Gillespie R. Anteroposterior instability of the knee: a sign of congenital limb deficiency. J Pediatr Orthop 1983;3(4):467-74.

Wagner H. Operative lengthening of the femur. Clin Orthop 1978; 136: 125-42.

Westin GW. Femoral lengthening using a periosteal sleeve: report of twenty-six cases. J Bone Joint Surg [Am] 1967;49-A:836-54. 